\title{
ANAESTHETIC MANAGEMENT OF A CASE OF GLOMUS JUGULARE CASE
}

\author{
Vinaya R. Kulkarni ${ }^{1}$
}

${ }^{1}$ Associate Professor, Department of Anaesthesiology, BJG Medical College, Pune, India.

\section{ABSTRACT}

\section{BACKGROUND}

Glomus Jugulare is a tumour arising from the glomus body at the dome of the jugular bulb. It is usually being and slow growing but can be locally invasive. Surgical removal of this tumour under anaesthesia involves many risks. This case report describes the transmastoid removal and perioperative anaesthetic management of a 55-year-old female patient with glomus jugulare. Vigilant monitoring and maintenance of a good depth of anaesthesia avoided all probable complications of this tumour in this patient and the tumour was removed successfully.

\section{KEYWORDS}

Glomus, Anaesthetic Management.

HOW TO CITE THIS ARTICLE: Kulkarni VR. Anaesthetic management of a case of glomus jugulare case. J. Evolution Med. Dent. Sci. 2017;6(1):67-70, DOI: 10.14260/Jemds/2017/17

\section{BACKGROUND}

Glomus tumour is a rare tumour which arises from the glomus body which is situated in the dome of the jugular bulb near tympanic branch of ninth nerve or in the middle ear. ${ }^{1}$ Glomera are the vessels of capillary or precapillary size lined by uniform large epithelioid cells that fail to stain with chromium salts. Two types described are glomus jugulare and glomus tympanicus. It arises from tissues within dome of jugular bulb, in the bone between bulb and hypotympanicum and along auricular branch of vagus. ${ }^{2}$

It is a slow growing tumour that infiltrates and invades bone of jugular fossa, jugular bulb, tympanic membrane, mastoid process, facial nerve, nerves of jugular foramen, labyrinth, fifth cranial nerve and cranial cavity and extends into nasopharynx. It may compress sigmoid sinus and jugular bulb from without or protrude polyp like into the bulb and internal jugular vein. It can rapidly extend intracranially. Microscopically it is a rich network of vascular spaces lined by large epithelioid cell. It can be approached through mastoid or through skull base for its removal. ${ }^{2}$

\section{CASE REPORT}

A 55-year-old female patient weighing $50 \mathrm{~kg}$ presented to outpatient department with a history of tinnitus in right ear with hearing loss since four years (Figure 1). She had facial palsy three years ago from which she had recovered partially. She also complained of ear discharge from right ear since three months and dysarthria. She was hypertensive taking amlodipine $5 \mathrm{mg}$ once a day. She was operated uneventfully for cataract three years ago under local anaesthesia.

On examination patient was pale and had pulse rate of 80 per min. Blood pressure was 150/80 mm Hg. Rest of the systemic examination was normal. Sensory and motor systems were normal with no evidence of cranial nerve

\section{Financial or Other, Competing Interest: None.}

Submission 28-11-2016, Peer Review 22-12-2016,

Acceptance 28-12-2016, Published 02-01-2017.

Corresponding Author:

Dr. Vinaya R. Kulkarni,

Department of Anaesthesiology,

BJG Medical College,

Pune, India.

E-mail: vinayabjmc@yahoo.com

DOI: $10.14260 /$ jemds $/ 2017 / 17$

\section{(c) $(1)$}

involvement ECG showed ST depression in leads II, III, avF, V4 to V6. CT scan of brain and HRCT of temporal bone showed a soft tissue mass in the right middle ear cavity extending into epitympanum, meso and hypotympanum and ht mastoid antrum (Figure 2). CT value 35-40 HU with opacification of mastoid "?<ceils In view of a history of pulsatile mass, these findings were suggestive of glomus jugulare tumour.

\section{Radiological Diagnosis is as follows}

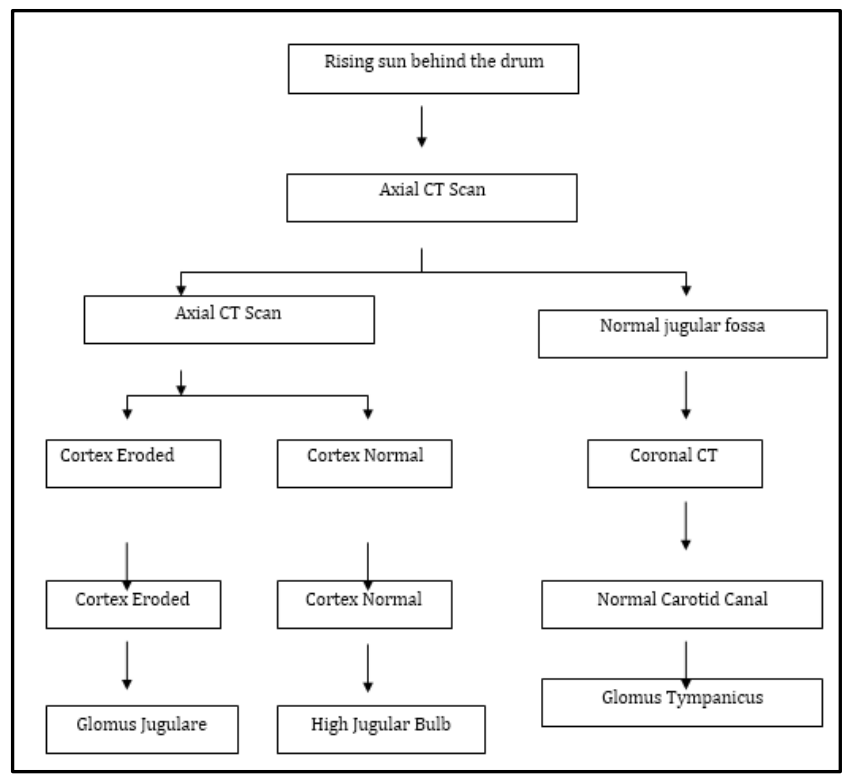

The absence of the normal crest of bone between the carotid canal and jugular fossa on lateral tomography is virtually diagnostic of a glomus jugulare tumour (Phelp's sign). ${ }^{3}$ Angiography with subtraction techniques represents an Important supplement to CT scans in the diagnosis and treatment of glomus tumours. It helps the surgeon to identify the various arterial supplies to the tumour. It helps to delineate extension into the jugular vein and carotid artery. It enables the diagnosis of multiple or bilateral lesions in cases where only one lesion has demonstrated symptoms. Finally, it aids in the differentiation of arterial and venous malformations from glomus tumours ${ }^{4}$. However, it was not done due to nonaffordability of the patent. 
Twenty-four hours Urinary VMA levels were $19 \mathrm{mg}$ (normal 2 to $8 \mathrm{mg}$ ), 2D Echo showed aortic sclerosis, grade IAR and EF 50\%. Lipid profile was normal. CT scan of abdomen did not show pheochromocytoma. Coagulation profile was normal. Haemoglobin was $9 \mathrm{gm} \%$, preoperatively patient received one blood transfusion. Patient was posted for transmastoid removal of the tumour.

On the night before surgery, patient received $10 \mathrm{mg}$ diazepam and her usual antihypertensives in the morning. Alpha blockers which are required in some cases were not given with physician advice. Adequate blood and FFPs were kept ready,

Prior to induction of anaesthesia, peripheral and central venous access was obtained. Central venous pressure was 5 $\mathrm{cm}$ of water. EGG monitor, pulse, oximeter, $\mathrm{ET} \mathrm{CO}_{2}$ NIBP was attached. Pre-induction blood pressure was 170/80 mm Hg and heart rate was 72 per min. Cardiac drugs including noradrenalin* were kept ready. Patient was predicated with intramuscular inj glycopylorate $6 \mu \mathrm{g} / \mathrm{kg}$ half hour before surgery inj fentanyl $1 \mathrm{ug} / \mathrm{kg}$ and inj midazolam $0.5 \mathrm{mg}$, ranitidine $1 \mathrm{mg} / \mathrm{kg}$ and granicetron $1 \mathrm{mg} / \mathrm{kg}$ intravenously a few minutes before induction of anaesthesia.

Induction was done with Pentothal sodium $5 \mathrm{mg} / \mathrm{kg}$, suxamethonium $2 \mathrm{mg} / \mathrm{kg}$ and lignocaine $1 \mathrm{mg} / \mathrm{kg}$. Anaesthesia was maintained with $50 \%$ oxygen in nitrous oxide supplemented with combination of isoflurane 0.4 to $1 \%$ propofol 6 to $10 \mathrm{mg} / \mathrm{kg}$ intermittently as TIVA to produce anaesthesia. Vecuronium $0.08 \mathrm{mg} / \mathrm{kg}$ was used for muscle $\mathrm{p}$ Intraoperative monitoring consisted of pulse, continuous ECG, NIBP, $\mathrm{ETCO}_{2}, \mathrm{SPO}_{2}, \mathrm{CVP}$, urine output and PNS. Ventilation was controlled to maintain an end-tidal $\mathrm{CO}_{2}$ tension of 34 to $38 \mathrm{~mm} \mathrm{Hg}$. The surgical procedure lasted for 4 hours. Blood loss was approximately $1000 \mathrm{ml}$ and two blood transfusions were given intraoperaively.

At the end of the procedure, residual neuromuscular blockade was reversed with neostigmine $0.04 \mathrm{mg} / \mathrm{kg}$ and glycopyrrolate $10 \mu \mathrm{g} / \mathrm{kg}$ given intravenously. Intravenous steroids were given. As the patient had an adequate respiratory effort and train of four showed no fade, her trachea was extubated and she was observed for half an hour in the operation theatre and then shifted towards.

In the postoperative period, patient received inj diclofenac sodium $75 \mathrm{mg} 8$ hourly for analgesia and her blood pressure was monitored every half hourly and remained stable. She developed right lower motor neuron facial palsy six hours postoperatively.

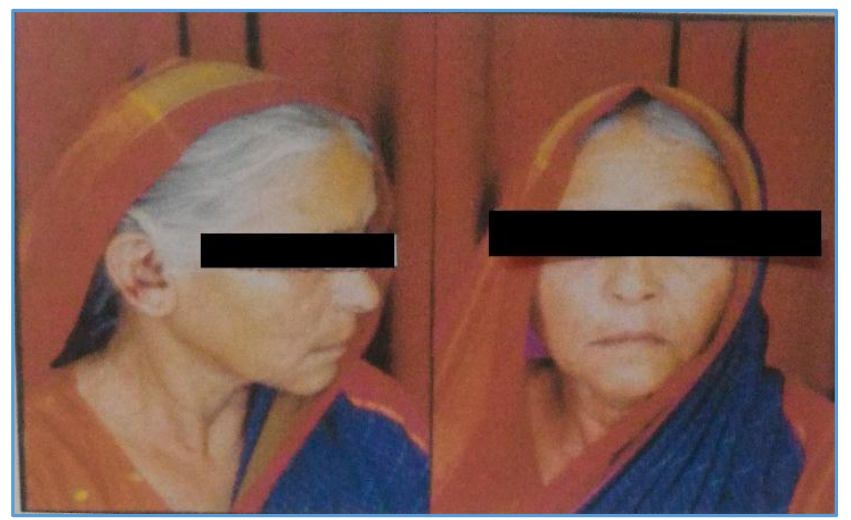

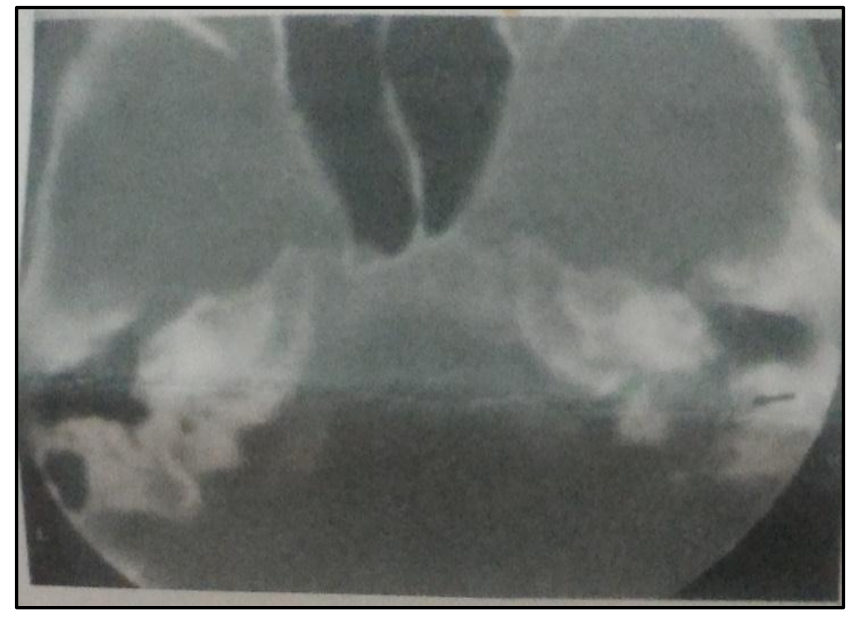

Figure 2. CT scan of temporal bone showing jugular fossa and eroded cortex

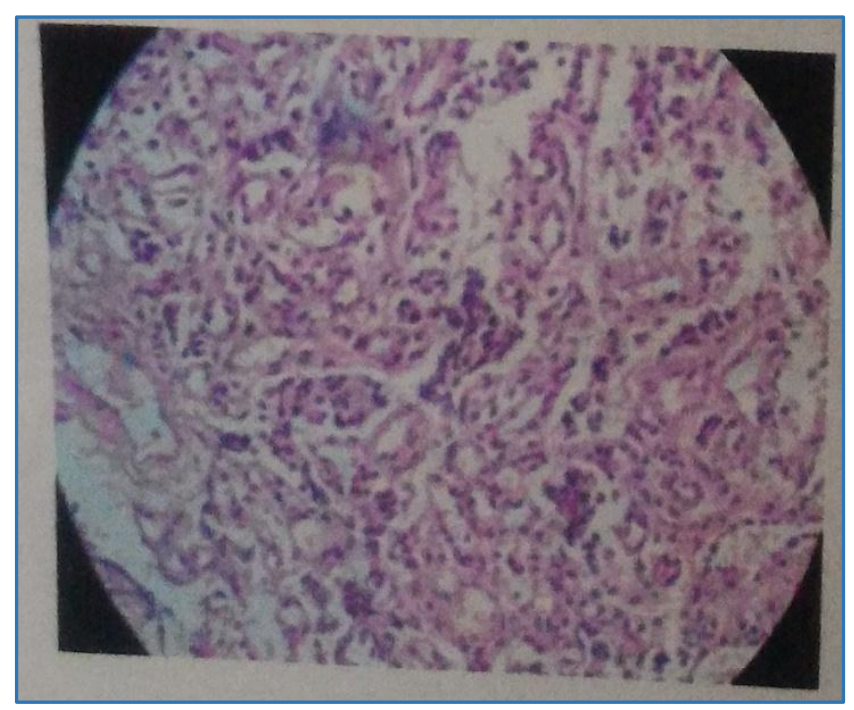

Figure 3. Histopathology of tumour showing network of vascular spaces lined by large epithelioid cells

\section{DISCUSSION}

Glomus jugulare is a rare highly vascular chemodectoma which presents a formidable challenge for anaesthesiologists. The likely problems are:

\section{Catecholamine secretion producing symptoms of a} pheochromocytoma $^{5}$

The incidence of catecholamine secreting glomus tumours is unknown but Levit et al ${ }^{5}$ reported 8 cases that contained 2.94 $\mathrm{mg}$ of norepinephrine per gram of tissue. Catecholamine levels of 3 to 5 times normal are required to produce clinical symptoms and glomus tumours may secrete several amounts several times normal and be subclinical. ${ }^{3}$

\section{Serotonin secretion producing carcinoid like syndrome}

Glomus tumour releases hydroxytryptophan, a precursor of serotonin and histamine, intraoperatively. Histamine and bradykinin released during surgical manipulation can cause profound hypotension and even shock. ${ }^{6}$

Figure 1. Patient having right facial paresis 


\section{Aspiration and airway obstruction following tumour resection}

Cranial nerve palsies can either manifest at the time of presentation or occur following tumour resection, Cranial nerves which are at risk are vagus, glossopharyngeal and hypoglossal (Jugular foramen syndrome). Recurrent aspiration, upper airway obstruction and difficulty in handling secretions are commonly faced problems. ${ }^{6}$

\section{Hydrocephalus and raised intracranial pressure}

Invasion of posterior fossa may obstruct aqueduct of sylvius causing hydrocephalus, raised ICT and may need shunting. It is common for this tumour to invade IJV and projections may extend into the right atrium. In the past, sitting position was used to facilitate exposure 6 . Now a day, lateral position is preferred to decrease risk of venous air embolism.

\section{Impaired gastric emptying}

Jackson et $\mathrm{a}^{6}$ observed that the perioperative management of patients undergoing surgical resection of glomus tumour is associated with gastrointestinal complications like ileus. They postulated that a fall in CCK which they found to be twice as great as the patients with nonglomus tumour (Skull base tumours) which might lead to failure of gastric emptying. Hence antiemetic prophylaxis is of utmost importance in these patients. Some patients may need tracheostomy and/or feeding gastrostomy postoperatively. ${ }^{6}$

\section{Venous air embolism}

The risk associated with resection of glomus tumour is due to involvement of jugular vein or need to open the sigmoid sinus. 5.6

\section{Blood loss}

This is a highly vascular tumour which bleeds profusely at slightest trauma with very little tendency for the bleeding to stop by itself as the vascular spaces have no contractile elements.1.6 Sigmoid sinus, inferior petrosal sinus and the tumour itself are the major sources of bleeding. ${ }^{6}$ Preoperative embolization diminishes intraoperative blood loss and shortens operative time. ${ }^{6}$ It is not used widely due to risk of morbidity, stroke and death. Other measures which can be carried out to reduce intraoperative blood loss are hypotensive anaesthesia 2.6 ligation of external carotid and jugular vein and slight head up position.2.6 Preoperative evaluation should include arteriography to evaluate location and blood supply to the tumour and venography to detect extension into IJV. This was not done in our patient as she belonged to very low socioeconomic class. Intracranial and extracranial involvement can be defined more precisely with MRI which shows multiple areas of no signal produced by blood vessels within tumour mass ${ }^{1}$. MRI was not done as the facility is not available in our institute.

Management of anaesthesia is influenced by all the above associated conditions. A careful history and physical examination are crucial. Symptoms include severe hypertension, sweating, diarrhoea, flushing and headache, All patients should be checked for serum and urine catecholamine levels and their breakdown products.5.6 Preoperative alpha and beta blockade may be necessary as prophylaxis with prazosin 8 to $12 \mathrm{mg}$ or phenoxybenzamine $10 \mathrm{mg}$ twice daily up to $100 \mathrm{mg} /$ day, Intraoperatively sodium nitroprusside 5.6 may be necessary to control hypertension and noradrenaline for hypotension, Similarly octreotide a long acting somatostatin analogue can be started two weeks prior in symptomatic patients in a dose of 100 jig subcutaneously two to three times daily. 6 Ketanserin may be used to treat a hypertensive carcinoid-like crisis as infusion of $5 \mathrm{mg} / \mathrm{hr}^{6}$ postoperatively, octreotide should be continued for 72 hours and slowly weaned over several days.

Preoperatively a careful history and physical examination to rule out the potential problem of airway compromise is needed. If patient gives history of previous head and neck surgery, an assessment of vocal cord function and position is important. Anaesthesiologist should be aware of nerve sacrifice or damage intraoperatively. Patient can develop oedema around these cranial nerves and can present with stridor which may need intubation or even tracheostomy. The risk of aspiration may require intubation, intermittent nasogastric suction postoperative total parental nutrition.5.6 Involvement of IJV may require opening of sigmoid sinus by surgeon.

Anaesthetic management in the setting of intracranial hypertension should follow the same general principles of neuroanaesthesia as for other intracranial mass lesions ${ }^{5,2,6}$ including use of drugs to decrease ICP, avoidance of halogenated agents except in tow concentrations and only after hyperventilation has been established. Controlled ventilation should be used to produce hypocarbia. Careful positioning, diuretics, mannitol and fluid restriction may be indicated.

It is very important to appreciate the risk of massive blood loss. An arterial line, Foley catheter, CVP or PA catheter for monitoring of volume status is necessary. If both IJVs are involved by tumour, then femoral vein should be used for CVP monitoring. Two large peripheral IV lines should be ready. Controlled hypotensive anaesthesia with even use of nitroprusside may be needed $1.5,2,6$

Venous air embolism (VAE) is a hazard if IJV is opened for removal of the tumour. ${ }^{2}$ Monitors to detect air embolism are indicated. Potential adverse effects of $\mathrm{N}_{2} \mathrm{O}$ should be recognized if VAE occurs. Early proximal and distal vein ligation and even cardiopulmonary bypass may be necessary in some cases. ${ }^{6}$ If carotid artery is to be occluded intraoperatively, some form of assessing adequacy of cerebral perfusion which includes EEG, SSEP, transcranial Doppler may be necessary. ${ }^{6}$

If surgeon finds it necessary to identify facial nerve, avoidance of profound skeletal muscle paralysis is necessary. ${ }^{6}$ Patient can land up in hypertensive crisis at the time of induction which can require administration of alpha or beta blockers or can land in circulatory collapse and shock after removal of tumour which might respond only to noradrenaline which is to be kept ready.5.6

The resected tumour was confirmed to be glomus tumour histopathologically (Figure 3).

This case thus highlights the problems which may be encountered in patients who present with glomus jugulare, a rare tumour which is a fascination for ENT surgeon and nightmare for anaesthesiologists. It emphasizes the importance of knowledge of speed and properties of this tumour, preoperative optimization of patient status which contributes to an uneventful intraoperative course due to good haemodynamic monitoring. 


\section{Acknowledgements}

We are grateful to the ENT department, BJ Medical College and Sassoon General Hospitals, Pune for their cooperation.

\section{REFERENCES}

[1] Jackson CG. Surgery for benign tumours of the temporal bone. In: Glasscock III ME, Gulya AJ, edts. Surgery of the ear. $5^{\text {th }}$ edn. Hamilton, Ontario: BC Decker Inc 2003:71442.

[2] Pasternak JJ, Lanier WL. Diseases affecting the brain. In: Hines RL, Marschall KE, edts. Stolting's Anesthesia and coexisting diseases. $6^{\text {th }}$ edn. Philadelphia: Elsevier Saunders 2012:218-54.
[3] Cheesman AD. Glomus and other tumours of the ear. In: Kerr AG, Booth JB, edts. Scott-Brown's otolaryngology: head and neck surgery. $5^{\text {th }}$ edn. London: ButterworthHeinemann 1988:546-53.

[4] Pansier SC, Edelstein DR. Tumours of the middle ear and mastoid. Paparella MM, Shumrick DA, Gluckamn JL, et al. edts. Otolaryngology, Vol II. 3rd edn. Philadelphia: WB Saunders, Harcourt Brace Jovanovich, Inc 1991:1461-3.

[5] Ghani GA, Sung YF, Per-Lee JH. Glomus jugulare tumoursorigin, pathology and anaesthetic considerations. Anaesth Analg 1983;62(7):686-91.

[6] Jensen NF. Glomus tumours of the head and neck: anaesthetic considerations. Anaesth Analg 1994;78(1):112-9. 